\title{
Extending "SafeGauge for Nutrients" to rainfed dairy systems in Victoria, Australia
}

\author{
$\underline{\text { T. Thayalakumaran }}^{\mathrm{a}}$, K. Barlow ${ }^{\mathrm{a}}$ and P. Moody \\ ${ }^{a}$ Agriculture Research Division, Department of Economic Development, Jobs, Transport and Resources, \\ Victoria. ${ }^{b}$ Department of Science, Information Technology and Innovation, Queensland
}

\section{Email: thabo.kumaran@ecodev.vic.gov.au}

\begin{abstract}
As agricultural systems continue to intensify, there is a need for farmers and farm advisors to understand how soil, climate and management interactively affect nitrogen losses at the paddock scale through the various pathways. This is particularly the case in dairy systems because of the complexity of nitrogen inputs including fertilisers, dairy effluent and grazing which are all managed on a paddock basis.

Computer-based decision support tools have been in use to build farm advisors' capacity to identify high risk nutrient loss environmental conditions and management practices specific to a particular paddock or farm. SafeGauge for Nutrients uses site specific soil and rainfall information in combination with user-entered management practices (including inputs of nutrients) to assess the risk of off-site nutrient movement to surface water (by runoff) and groundwater (by drainage), as well as the atmosphere (by denitrification). SafeGauge is currently configured for use in the sugarcane cropping systems of Queensland, Australia.

In this paper, we present the design of a nitrogen loss decision support tool for high rainfall dairy systems based on SafeGauge for Nutrients. Users define the paddock being simulated through a range of inputs including: paddock position in the landscape (slope, depth to groundwater, distance to watercourse and area of the paddock), soil type, animal management (number of cows per paddock, grazing rule, grain/forage fed per cow) and paddock management (fertiliser/manure/effluent usage), a subjective estimate of actual dry matter yield for the previous rotation, and target dry matter yield for the current rotation. Information on management practices in combination with a pasture-nitrogen response function and animal nitrogen conversion efficiency are used to estimate pasture nitrogen demand for a grazing rotation and nitrogen contribution to the paddock by urine/dung. Surplus nitrogen for the day in the grazing paddock is determined from pasture nitrogen demand, nitrogen from urine/dung, fertiliser/effluent/manure nitrogen, nitrogen fixation to soil and nitrogen losses on the previous day. Finally the tool predicts the daily risks of nitrogen loss via the various pathways using daily average runoff, deep drainage and soil moisture (obtained by running a biophysical model for 50 years for various soil types and climatic zones) in wet, average and dry years. Percentage water filled pore space derived from daily soil moisture values determines the atmospheric losses via denitrification. The risks are then modified to account for differences in slope and paddock position in the landscape. The tool provides a visual representation of the risk in all three pathways as well as a summary report on nitrogen input/output balance for the current and last grazing periods of the selected grazing paddock. Results are comparable to the available field measured data and modelled outputs from biophysical models.
\end{abstract}

Keywords: $\quad$ Decision Support System (DSS), water quality, denitrification, $N$ loss pathways 
Thayalakumaran et al., Extending SafeGauge for Nutrients to dairy in high rainfall zones of Victoria, Australia

\section{INTRODUCTION}

Environmental impacts of pasture based agricultural systems has long been acknowledged in various countries including Australia (Di and Cameron 2002; Dougherty et al. 2004; Eckard et al. 2004b; Wilcock et al. 2007). Off-farm nitrogen $(\mathrm{N})$ losses from dairy systems through runoff, deep drainage and emissions of greenhouse gases can have significant environmental impacts as well as affecting the efficiency of $\mathrm{N}$ use in production. Nitrogen-use efficiency in Australian dairy systems ranges from 15 to 50\% (Gourley et al. 2012), despite the comprehensive knowledge about pasture production response to $\mathrm{N}$ and the environmental consequences of excess $\mathrm{N}$ availability in the soil. Furthermore, over the last two decades $\mathrm{N}$ inputs to dairy systems have rapidly increased in the form of increased $\mathrm{N}$ fertiliser application, increased brought-in feed with high N content and increased farm intensity (Gourley et al. 2012; Burkitt, 2014).

There are a range of tools which can be used to inform and develop our understanding of $\mathrm{N}$ export from dairy pastures. Biophysical models integrate complex biological and physical processes are used to investigate how $\mathrm{N}$ inputs to farms via various management practices, pasture, soil and climate interact, and how the $\mathrm{N}$ can be efficiently utilized to minimize off-farm losses (Bryant et al. 2011). However, many such models are complex and input intensive and thus cannot be used easily by land owners or farm advisors. As an alternative, computer-based decision support tools have been developed to build farm advisors' and farmers' capacity in identifying high risk nutrient loss environmental conditions and management practices specific to a dairy paddock or farm. Decision support tools such as the Farm Nutrient Loss Index (Melland et al. 2004) operate on an annual average basis but do not capture the temporal sensitivity of nitrogen management. Both the changes in environmental conditions and the tactical decisions of farmers arise on short temporal scale, therefore the decision support tools should be able to capture these changes and respond to the pasture-soilclimate-management interactions at those temporal scales. SafeGauge for Nutrients, developed for the Queensland sugar industry assesses the risk of off-site nutrient movement to surface water (by runoff) and ground water (by drainage) as well as the atmosphere (by denitrification) at daily time step (Moody et al. 2008).

In this paper, we present the design of a nitrogen loss decision support system for rainfed dairy systems using SafeGauge for Nutrients as a base tool. The main purpose is to help farm advisors to identify the risk of $\mathrm{N}$ losses and the relative size of various $\mathrm{N}$ loss pathways (runoff, drainage and denitrification) on a daily time scale for a user selected grazing paddock and time period.

\section{SAFEGAUGE FOR DAIRY (SAFEGAUGE_DAIRY)}

\subsection{Scope/capacity}

SafeGauge for Nutrients was used as a basis for developing a tool which can define $\mathrm{N}$ inputs, $\mathrm{N}$ flows and losses from rainfed dairy paddocks (SafeGauge_dairy). In developing SafeGauge_dairy, minimal changes were made to the original structure of SafeGauge, highlighting that the tool can be further developed for a range of industries. SafeGauge_dairy is intended to be used as part of training for advisors both within the Fertcare Carbon Farming and Extension Program and in the ongoing development of advisors who undertake Fertcare training. The tool will assist in "calibrating" advisors ability to identify high risk N loss situations on rainfed dairy farm paddocks, and develop an understanding of nutrient loss and management. Initially SafeGauge_dairy will be a CD version to be used as a training tool; it is not anticipated that it would be used each time an advisor develops a nutrient plan or makes a fertiliser recommendation.

SafeGauge_dairy qualitatively assesses the potential risk for off-site nitrogen $(\mathrm{N})$ losses by runoff, drainage and denitrification as a result of on-farm $\mathrm{N}$ use and management in grazing dairy paddocks. The tool, by integrating user-provided information on paddock/site characteristics, $\mathrm{N}$ inputs to the paddock and paddock management options, allows the user to assess the risks in different pathways due to a single factor or several factors combined. SafeGauge_dairy operates on a paddock scale and assesses the risks for the current and last grazing rotations on a daily basis.

\subsection{Structure}

SafeGauge_dairy is underpinned by a database of runoff, drainage and soil moisture for a range of climate stations and soil types, pasture yield response to $\mathrm{N}$ fertilizer function which have previously been used in the Dairy Nitrogen Fertilizer Advisor (Stott et al. 2015), and a database of dairy supplementary feed, fertilizer mixes and their $\mathrm{N}$ content (Gourley et al. 2010). Figure 1 shows a flow chart of inputs and the risk estimation processes in SafeGauge_dairy. User inputs, estimation of daily water losses, soil $\mathrm{N}$ inputs and outputs and daily available $\mathrm{N}$ estimation are the main components. 
Thayalakumaran et al., Extending SafeGauge for Nutrients to dairy in high rainfall zones of Victoria, Australia

\subsection{User Inputs}

User input details for SafeGauge_dairy have been grouped into (a) Location/soil details (b) Pasture and animal management (c) Fertiliser and effluent management for the last and current rotations and, (d) Block/grazing paddock characteristics.

(a) Location/soil details: In this section, the user is required to enter the location of the paddock (latitude, longitude, Australian state), select the soil group based on the description provided that matches the paddock and also select whether the risk assessment is for an average, wet or dry year.

(b) Pasture and animal management: The user selects the pasture type, percent legume mix, ground cover, grazing rule, number of cows grazed, pre and post grazing dry mass and supplements fed to the cows. These details are entered for the last and current grazing rotations. Details entered in this section facilitate the estimation of $\mathrm{N}$ inputs/outputs of the grazing paddock other than fertilizer and effluent and include $\mathrm{N}$ intake by pasture to support the grazing cows, the animal excreta $\mathrm{N}$ input to the paddock and $\mathrm{N}$ fixed in soil by the legumes.

(c) Fertiliser and effluent management: The user is required to enter the type of fertilizer and effluent applied, date applied and method applied.

(d) Block characteristics: The user is required to select block characteristics such as slope, distance to water course and depth to ground water from the ranges provided, and also enters the area of the paddock.

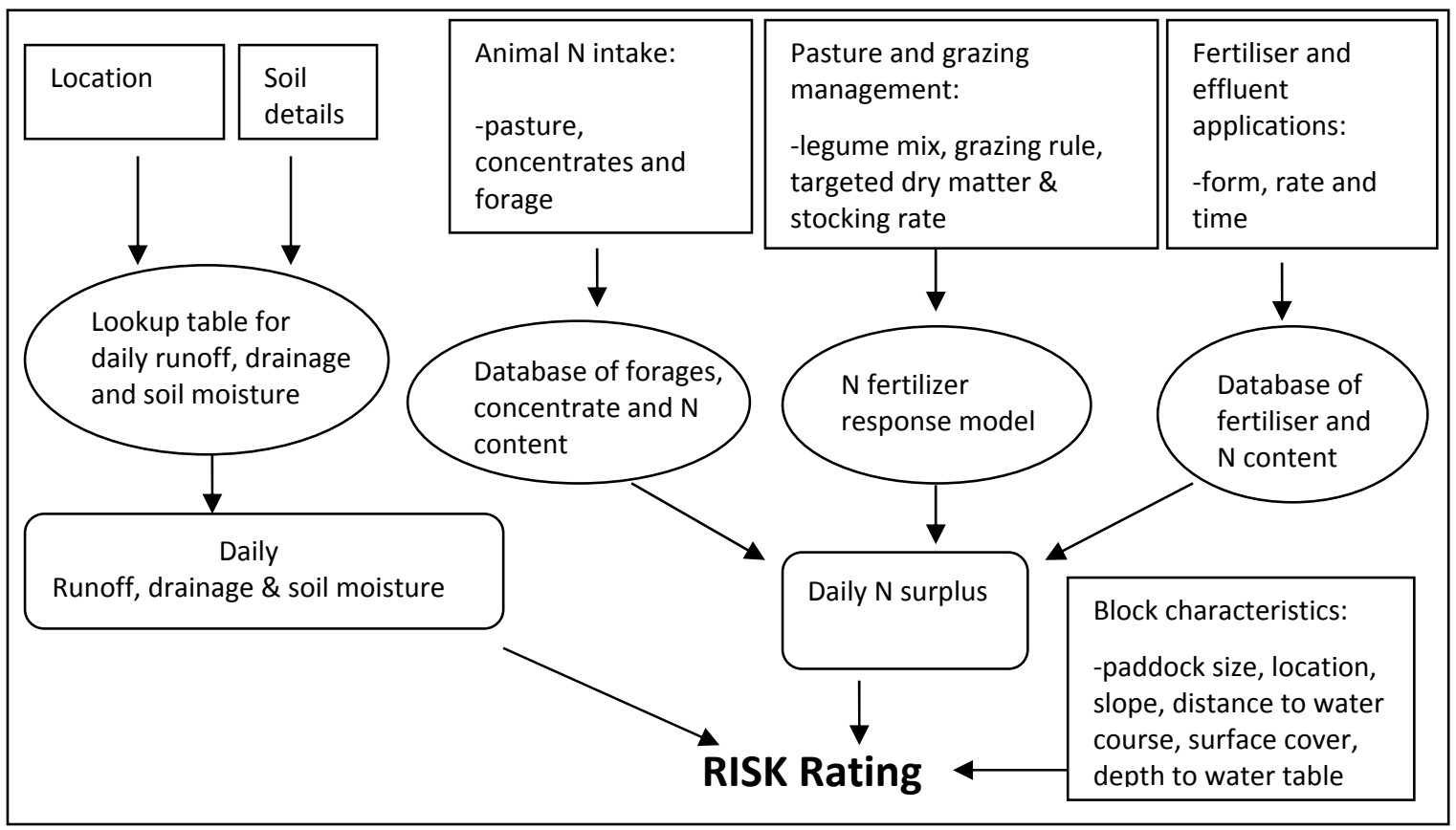

Figure 1. Flowchart illustrating the inputs (rectangular blocks), calculations (oval) and outputs (rounded rectangles) used to quantify risk ratings in SafeGauge_dairy.

\subsection{Lookup table for daily runoff, drainage and soil moisture}

Daily average runoff, drainage and soil moisture time series (look up table) were derived by running a 1D pasture growth model run in CAT (Weeks et al 2008) for combinations of soil groups (relevant to Victoria), climate (for the stations in high rainfall zone, Victoria), and a slope of $0.5 \%$ for 50 years. Soil characteristics were from McKenzie et al. (2000) and climate data were from the SILO database. Daily average runoff, drainage and soil moisture were calculated for wet, dry and average years based on the categorization of 50 years of annual rainfall into wet (top $20^{\text {th }}$ percentile), dry (bottom $20^{\text {th }}$ percentile) and average. The userentered inputs are used to select daily runoff, drainage and soil moisture data specific to the paddock characteristics and the year type from the embedded lookup table.

\subsection{Estimation of soil $\mathrm{N}$ inputs and outputs}

Estimation of pasture growth and response to nitrogen is a complex process usually accomplished by deterministic pasture growth models. We used a simplified but robust, existing functional relationship. 
Thayalakumaran et al., Extending SafeGauge for Nutrients to dairy in high rainfall zones of Victoria, Australia

National $\mathrm{N}$ fertilizer responses model on dairy farms was used in the Dairy Nitrogen Fertilizer Advisor (Stott et al. 2015). It is a production function relating single $\mathrm{N}$ application rates to pasture consumption over a grazing rotation, at a particular season (summer, winter, spring and autumn) and in a particular region. As the pasture yield is scaled (0-1), user inputs such as the fertilizer amount applied for the last rotation, the corresponding dry matter produced (pre-grazing dry mass) in that paddock and the post-grazing dry mass are required to estimate the absolute pasture dry mass consumed. User entered details of pasture management with the $\mathrm{N}$ fertilizer response function allows the estimation of $\mathrm{N}$ required or used for the animal-consumed pasture in the current rotation.

Commonly used supplements in Australian dairy farms (concentrates and forages) and their $\mathrm{N}$ content is available in a database (Gourley et al. 2010). User input details of pasture consumption, supplements fed to cows, and the database enable the estimation of total $\mathrm{N}$ intake by animals. Animal $\mathrm{N}$ conversion efficiency of 65 to 85 was reported by Gourley et al. (2010) however, an average value of $70 \%$ was used in SafeGauge dairy to calculate the N contribution to the paddock as animal excreta during grazing. i.e. $70 \%$ of the total $\mathrm{N}$ intake by animals will be deposited as excreta. From this excreta $1 / 3$ is estimated to be dung $\mathrm{N}$ and $2 / 3$ as urine $\mathrm{N}$. This separation is essential as the urine $\mathrm{N}$ is the main, immediate contributor to $\mathrm{N}$ loss pathways. It was further assumed that on average $10 \%$ of the urine $\mathrm{N}$ volatilizes (Johnson et al. 2008) though variable rates of volatilization can be different between seasons. On average, cows are expected to spend $85 \%$ of their time in paddocks for grazing. Thus,

Excreted urine_N $=$ total animal $N$ intake $* 0.7 * 0.66 * 0.9 * 0.85$

Regression equations by Ledgard et al. (2001) and Unkovich (2012) were used to estimate N fixed in shoots for white clover and lucerne respectively. Ledgard et al. (2001) was preferred for white clover as the function takes into account of the influence of fertilizer $\mathrm{N}$ on $\mathrm{N}$ fixation. A multiplication factor of 1.75 and 2 times the herbage $\mathrm{N}$ fixed were used for white clover and legume respectively, to estimate total $\mathrm{N}$ fixed (Unkovich, 2012). Data on initial soil mineral N status in dairy soils are difficult to obtain. However, it is assumed 10 $\mathrm{mg}-\mathrm{N} \mathrm{kg}$ of soil ${ }^{-1}$ exists as ammonium and nitrate (from default value used in DairyMod) and this does not change with time.

A database of commonly used fertilisers in dairy and their $\mathrm{N}$ content (Gourley et al. 2010) enables the estimation of fertilizer $\mathrm{N}$ input to soil.

\subsection{Estimation of daily available $\mathbf{N}$ for losses (Daily $\mathbf{N}$ surplus)}

Based on the user entered details in sections (a), (b) and (c), the embedded database and the functional relationships, the available $\mathrm{N}$ in the selected grazing paddock is estimated on a daily time step as,

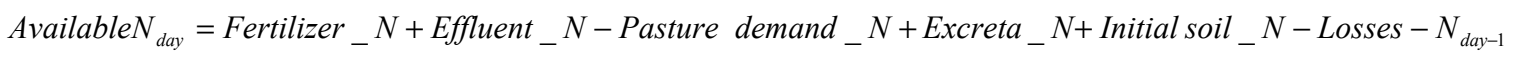

The estimated available $\mathrm{N}$ is in the form of ammonium and nitrate. Although both forms of $\mathrm{N}$ contribute to losses by runoff, only nitrate $\mathrm{N}$ contributes to losses in denitrification and drainage (ammonium will be adsorbed by soil). To partition the estimated available $\mathrm{N}$ into ammonium and nitrate, the default nitrification rate in DairyMod was applied. DairyMod (Johnson et al. 2008) is a one-dimensional, biophysical model developed for New Zealand and Australian grazing systems.

$$
\text { Rate of nitrification }=V_{\max _{-} \mathrm{NO}_{3}} \times\left[\frac{\mathrm{Soil}_{\mathrm{NH}_{4}}}{\text { Soil }_{\mathrm{NH}_{4}}+\mathrm{NH}_{4} \text { half response }}\right]
$$

where, $\quad V_{\max _{-} \mathrm{NO}_{3}}=20 \mathrm{mg} \quad \mathrm{N} \mathrm{kg}^{-1} \mathrm{day}^{-1} ; \quad \mathrm{Soil}_{\mathrm{NH}_{4}}=$ ammonium concentration in the soil; $\mathrm{NH}_{4}$ _half response $=90 \mathrm{mg} \mathrm{Ng} \mathrm{soil}^{-1}$

\subsection{Daily $\mathbf{N}$ loss ratings in various pathways}

The daily available $\mathrm{N}$ combined with location-specific runoff and drainage and the paddock area was used to derive a qualitative risk of $\mathrm{N}$ movement to surface waters and ground water. It was assumed that denitrification occurs when percent saturated pores is greater than $60 \%$. Daily soil moisture values derived from the database and the porosity of the soils were used to estimate percent water filled pore space. Denitrification rate of $0.1 \mathrm{mg} \mathrm{N} \mathrm{kg}$ of soil ${ }^{-1}$ day $^{-1}$ if available $\mathrm{NO}_{3}$ is $>20 \mathrm{mg} \mathrm{kg}$ of soil ${ }^{-1}$ and a reduced rate of $0.05 \mathrm{mg} \mathrm{N} \mathrm{kg}$ of soil $^{-1}$ day $^{-1}$ if $\mathrm{NO}_{3}$ is $<20 \mathrm{mg} \mathrm{kg}$ of soil $^{-1}$ were used (default values in DairyMod). 
Thayalakumaran et al., Extending SafeGauge for Nutrients to dairy in high rainfall zones of Victoria, Australia

Nitrogen loss rating tables (Table1) were developed based on a series of integrated DairyMod_Howleaky model (Thayalakumaran et al. 2013) runs for high rainfall zone dairy paddocks and some measured data (Barlow et al. 2007). Daily $\mathrm{N}$ losses by runoff were found to vary from $0-6 \mathrm{~kg}-\mathrm{N} \mathrm{ha}{ }^{-1}$, by drainage from 0 to $10 \mathrm{~kg}-\mathrm{N} \mathrm{ha}{ }^{-1}$ and denitrification from $0-1 \mathrm{~kg}-\mathrm{N} \mathrm{ha}{ }^{-1}$. Based on the measured and modelled $\mathrm{N}$ loss ranges for each of the three pathways the following rating tables were derived.

Table 1. N loss rating table

\begin{tabular}{|c|c|c|c|c|c|}
\hline \multicolumn{2}{|l|}{ Runoff N } & \multicolumn{2}{|l|}{ Drainage $\mathrm{N}$} & \multicolumn{2}{|l|}{ Denitrification N } \\
\hline $\mathrm{N}$ Loss $\left(\mathrm{kg}-\mathrm{N} \mathrm{ha}{ }^{-1}\right.$ day $\left.^{-1}\right)$ & Rating & $\mathrm{N}$ Loss $\left(\mathrm{kg}-\mathrm{N} \mathrm{ha}{ }^{-1}\right.$ day $\left.^{-1}\right)$ & Rating & N Loss $\left(\mathrm{kg}^{-\mathrm{N} \mathrm{ha}}{ }^{-1}\right.$ day $\left.^{-1}\right)$ & Rating \\
\hline$<1$ & $\mathbf{0}$ & $<1$ & $\mathbf{0}$ & $<0.05$ & $\mathbf{0}$ \\
\hline $1-2$ & 1 & $1-3$ & 1 & $0.05-0.1$ & 1 \\
\hline $2.1-3$ & 2 & $3.1-5$ & 2 & $0.11-0.5$ & 2 \\
\hline $3.1-4$ & 4 & $5.1-7$ & 4 & $0.51-1.0$ & 4 \\
\hline$>4$ & 8 & $>7$ & 8 & $>1.0$ & 8 \\
\hline
\end{tabular}

\subsection{Daily $\mathbf{N}$ loss risks in various pathways}

The daily $\mathrm{N}$ loss risks are then modified to account for differences in slope and paddock position in the landscape using information entered by the user. Daily risk of $\mathrm{N}$ loss in runoff is modified depending on the slope and distance to the water course, while the risk of $\mathrm{N}$ loss in drainage is modified for the slope and depth to ground water. Slope modifier is based on the CAT modelling results of runoff and drainage for a range of slopes in high rainfall zones. Modifiers for water table depth and distance to water course were adapted from the original SafeGauge for Nutrients.

Finally, risks are reported as daily risk index for current and last grazing rotations, and also in the form of gauges with scales in graphical form. In addition, a summary report with various $\mathrm{N}$ inputs and outputs of the paddocks is provided for the two grazing rotations.

\section{DISCUSSION AND CONCLUSIONS}

SafeGauge_dairy was applied to a field site with measured N losses and a few hypothetical scenarios. A dairy paddock of 5 ha on a dermosolic/redoxic hydrosol in Gippsland, Victoria was selected as an example as this block has leaching and denitrification measurements by Eckard et al. (2004a). Pasture was a rye grass and white clover mix ( $9 \%$ legume) with greater than $90 \%$ cover. Pasture was grazed for two days starting on $7 / 8 / 98$ and then on 27/9/98 with a stocking rate of 2.8 cows/ha. Pasture consumption was $1340 \mathrm{~kg} \mathrm{ha}^{-1}$ in both grazings. The cows were fed with triticale grains and hay forage at the rate of $3 \mathrm{~kg} \mathrm{cow}^{-1} \mathrm{day}^{-1}$ each. Fertiliser was applied on 27/7/98 and 19/10/98 as urea at the rate of $50 \mathrm{~kg} \mathrm{ha}^{-1}$ in each application. Paddock slope was $1 \%$, distance to water course was $>300 \mathrm{~m}$ and the depth to water table was greater than $1.5 \mathrm{~m}$. As shown in Table 2, the numbers from SafeGauge_dairy are in reasonable match with the measured $\mathrm{N}$ losses in leaching, $\mathrm{N}$ fixation and denitrification losses.

Table 2. Summary report from SafeGauge_dairy. Values in brackets are the measured values Eckard et al (2004a)

\begin{tabular}{|c|c|c|c|}
\hline Current grazing period & & $\underline{\text { Last grazing period }}$ & \\
\hline Fertiliser Applied (kg_N/block) & 115.0 & Fertiliser Applied (kg_N/block) & 0.0 \\
\hline Effluent Applied(kg_N/block) & 0.0 & Effluent Applied(kg_N/block) & 0.0 \\
\hline N_Urine and dung(kg_N/block) & $32.1(38.4)$ & N_Urine and dung(kg_N/block) & $23.0(28.9)$ \\
\hline N_Fixation in soil (kg_N/block) & $99.2(69.5)$ & N_Fixation in soil (kg_N/block) & $64.4(40.5)$ \\
\hline N_Pasture Uptake (kg_N/block) & 117.6 & N_Pasture Uptake (kg_N/block) & 115.0 \\
\hline $\mathrm{N}$ loss in runoff (kg_N/block) & 0.0 & $\mathrm{~N}$ loss in runoff (kg_N/block) & 0.0 \\
\hline $\mathrm{N}$ loss in drainage (kg_N/block) & $12.8(5)$ & $\mathrm{N}$ loss in drainage (kg_N/block) & $1.4(3.5)$ \\
\hline $\mathrm{N}$ loss in denitrification (kg_N/block) & 4.0 & $\mathrm{~N}$ loss in denitrification (kg_N/block) & 3.1 \\
\hline Balance(Inputs-Outputs) & 124.6 & & -30.7 \\
\hline
\end{tabular}

Figures $2 \& 3$ show the differences in the $\mathrm{N}$ loss risks for a hypothetical grazed pasture paddock on a low permeable soil and medium rainfall zone (Fig 2) and the same paddock on a high permeable soil in a high 
Thayalakumaran et al., Extending SafeGauge for Nutrients to dairy in high rainfall zones of Victoria, Australia

rainfall zone (Fig 3), during an average rainfall year. The risk index for drainage was high in the current grazing period in Figure $2 \mathrm{a}$ as opposed to Figure $2 \mathrm{~b}$ because of the coincidence of surplus $\mathrm{N}$ and a large rainfall event. In Figure 3b, though the $\mathrm{N}$ surplus did not change (as there was no changes to paddock management), several runoff risk days and drainage $\mathrm{N}$ loss risks over a continuous 7-day period were observed during the last grazing. These risks are driven by changes in runoff and drainage caused by the rainfall and the highly permeable nature of the soil.
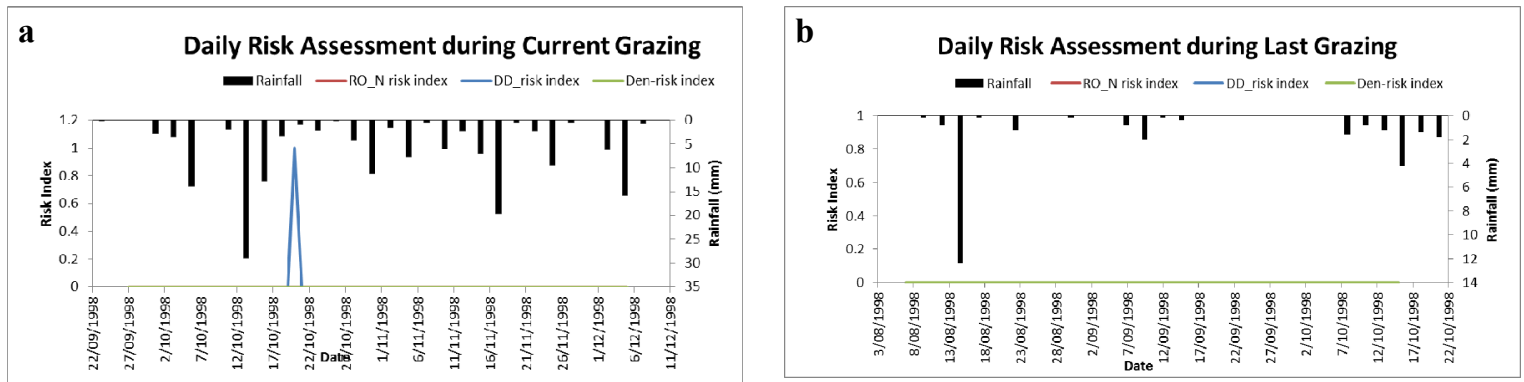

Figure 2. Graphical output of daily risks of N loss via various pathways SafeGauge_dairy (low permeability soil and medium rainfall zone during an average rainfall year). $\mathrm{RO}=$ runoff, $\mathrm{DD}=$ drainage, Den =denitrification)
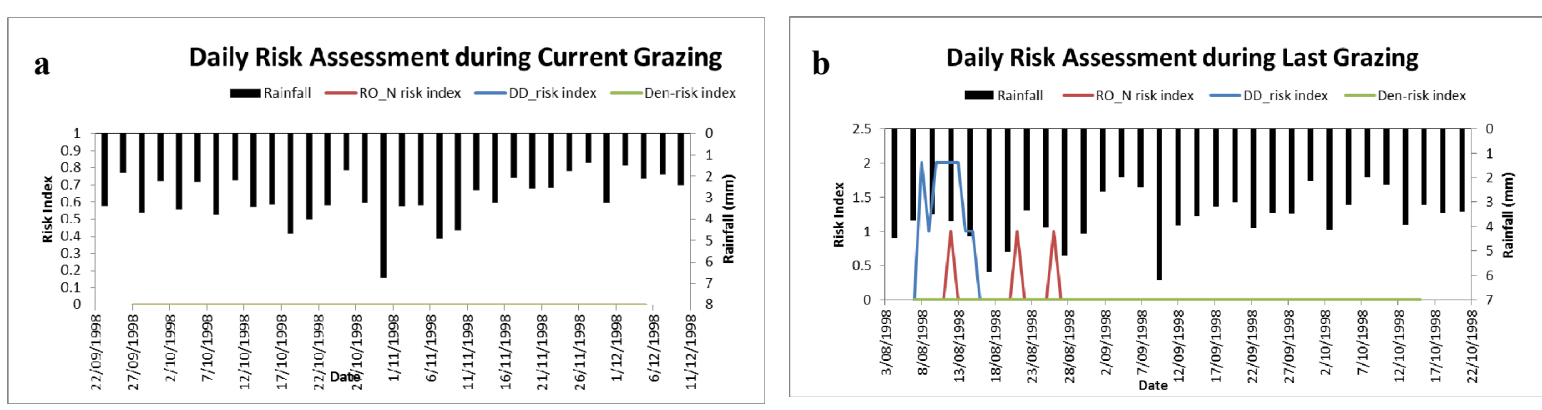

Figure 3. Graphical output of daily risks of $N$ loss via various pathways SafeGauge_dairy (permeable soil and high rainfall zone during an average rainfall year). $\mathrm{RO}=$ runoff, $\mathrm{DD}=$ drainage, Den =denitrification)

The testing of SafeGauge_dairy, though limited to a few observed and scenario runs, provides confidence for use in dairy grazing paddocks to identify risks of $\mathrm{N}$ losses and the relative magnitude changes to differences in management and environmental conditions, and their interaction. The next step is testing of SafeGauge_dairy with industry professionals for functionality, usability and logic.

\section{ACKNOWLEDGMENTS}

The work was funded by the Australian Government and Department of Economic Development, Jobs, Transport and Resources (DEDJTR), Victoria with in-kind support from Fertilizer Australia and the wider fertilizer industry. The authors acknowledge the efforts of Jeff Kraak, program manager of Fertilizer Australia and Graham Anderson (DEDJTR) for facilitating the permission to use SafeGauge for Nutrients as the base tool.

\section{REFERENCES}

Barlow, K., Nash, D., Hannah, M., Robertson, F. (2007). The effect of fertiliser and grazing on nitrogen export in surface runoff from rain-fed and irrigated pastures in south-eastern Australia. Nutrient Cycling in Agroecosystems 77, 69-82.

Bryant, J.R., Snow, V.O., Cichota, R., Jolly, B.H. (2011). The effect of situational variability in climate and soil, choice of animal type and $\mathrm{N}$ fertilisation level on nitrogen leaching from pastoral systems around Lake Taupo, New Zealand. Agricultural Systems 104, 271-280.

Burkitt, LL. (2014). A review of nitrogen losses due to leaching and surface runoff under intensive pasture management in Australia. Soil Research, 52, 621-636. http://dx.doi.org/10.1071/SR13351

Di, H.J., and Cameron, K.C. (2002). Nitrate leaching from temperate agroecosystems: sources, factors and mitigating strategies. Nutrient Cycling in Agroecosystems 64, 237-256. doi:10.1023/A:1021471 531188 
Thayalakumaran et al., Extending SafeGauge for Nutrients to dairy in high rainfall zones of Victoria, Australia

Dougherty, W.J., Fleming, N.K., Cox, J.W., Chittleborough, D.J. (2004). Phosphorus transfer in surface runoff from intensive pasture systems at various scales: a review. Journal of Environmental Quality 33, 1973-1988. doi:10.2134/jeq2004.1973

Eckard, R.J., White, R.E., Edis, R., Smith, A., Chapman, D.F. (2004a). Nitrate leaching from temperate perennial pastures grazed by dairy cows in south-eastern Australia. Australian Journal of Agriculture Research 55, 911-920.

Eckard, R.J., Chapman, D.F., White, R.E., Chen, D. (2004b). The environmental impact of nitrogen fertiliser use on dairy pastures. Australian Journal of Dairy Technology. 59 (2), 145-148.

Gourley, C.J.P., Dougherty, W.J., Aarons, S.R., Hannah, M.C. (2010). Accounting for Nutrients on Australian Dairy Farms. Final report. www.accounting4nutrients.com.au.

Gourley, C.J.P., Dougherty, W.J., Weaver, D.M., Aarons, S.R., Awty, I.M., Gibson, D.M., Hannah, M.C., Smith, A.P., Peverill, K.I. (2012) Farm-scale nitrogen, phosphorus, potassium and sulfur balances and use efficiencies on Australian dairy farms. Animal Production Science 52, 929944.http://dx.doi.org/10.1071/AN11337

Johnson, I.R., Chapman, D.F., Snow, V.O., Eckard, R.J., Parsons, A.J., Lambert, M.G., Cullen, B.R. (2008). DairyMod and EcoMod: biophysical pasture simulation models for Australia and New Zealand. Australian Journal of Experimental Agriculture 48, 621-631.

Ledgard, S.F., Sprosen, M.S., Penno, J.W., Rajendram, G.S. (2001). Nitrogen fixation by white clover in pastures grazed by dairy cows: temporal variation and effects of nitrogen fertilization. Plant and Soil 229, 177-187. doi:10.1023/A:1004833804002.

McKenzie, N.J., Jacquier, D.W., Ashton L.J. and Cresswell, H.P. (2000) Estimation of Soil Properties Using the Atlas of Australian Soils. CSIRO Land and Water Technical Report 11/00.

Melland, AR., Gourley, C.J.P., Smith, A.P, Tarbotton, I.S, Peverill, K.I. (2004). Developing a farm nutrient loss index for grazed pasture in Australia. SuperSoil 2004:3 ${ }^{\text {rd }}$ Australian New Zealand Soils Conference, 5-9 December 2004, University of Sydney, Australia. Website www.regional.org.au/au/asssi/

Moody, P.W., Blogg, D., LeGrand, J., Schroeder, B.L., Wood, A.W. (2008). 'SCAMP' and 'SafeGauge for Nutrients': two new decision support tools for minimising off-site movement of nutrients. Proc. Australian Society of Sugar Cane Technologists 30, 276-284.

Stott, K., Malcolm B., and Gourley C. (2015). The Dairy N fertilizer Advisor-a tool to predict optimal N application rates in grazed dairy pastures. Agricultural Research Division Technical report. Department of Economic Development, Jobs, Transport and Resources. Victoria.

Thayalakumaran, T., Vigiak, O., Beverly, C., Roberts, A., Stott, K., Robinson, B and Freebairn, D. (2013). Integrating two process-based models for assessing dairy system management impacts on $\mathrm{N}$ losses. In Piantadosi, J., Anderssen, R.S. and Boland J. (eds) MODSIM2013, 20th International Congress on Modelling and Simulation. Modelling and Simulation Society of Australia and New Zealand, December 2013, pp. 2506-2512. ISBN: 978-0-9872143-3-1. www.mssanz.org.au/modsim2013

Unkovich, M. (2012). Nitrogen fixation in Australian dairy systems: review and prospect. Crop \& Pasture Science 63, 787-804.

Weeks, A., Christy, B., Lowell, K., Beverly, C. (2008) The Catchment Analysis Tool: demonstrating the benefits of interconnected biophysical models. In 'Landscape Analysis and Visualisation.' (Eds C Pettit, W Cartwright, I Bishop, K Lowell, D Pullar and D Duncan) pp. 49-71. (Springer-Verlag: Berlin)

Wilcock, R.J., Monaghan, R.M., Thorrold, B.S., Meredith, A.S., Betteridge, K., Duncan, M.J. (2007). Landwater interactions in five contrasting dairy catchments: issues and solutions. Water Resources Research 7, 2.1-2.10. 